Article

\title{
Dry Etching of Copper Phthalocyanine Thin Films: Effects on Morphology and Surface Stoichiometry
}

\author{
Jaron G. Van Dijken ${ }^{1}$ and Michael J. Brett ${ }^{1,2, *}$ \\ 1 Department of Electrical and Computer Engineering, University of Alberta, Edmonton, \\ AB T6G 2V4, Canada \\ 2 NRC-National Institute for Nanotechnology, Edmonton, AB T6G 2M9, Canada \\ * Author to whom correspondence should be addressed; E-Mail: mbrett@ualberta.ca; \\ Tel.: +1-780-492-4438; Fax: +1-780-492-2863.
}

Received: 16 July 2012; in revised form: 16 August 2012 / Accepted: 20 August 2012 /

Published: 24 August 2012

\begin{abstract}
We investigate the evolution of copper phthalocyanine thin films as they are etched with argon plasma. Significant morphological changes occur as a result of the ion bombardment; a planar surface quickly becomes an array of nanopillars which are less than $20 \mathrm{~nm}$ in diameter. The changes in morphology are independent of plasma power, which controls the etch rate only. Analysis by X-ray photoelectron spectroscopy shows that surface concentrations of copper and oxygen increase with etch time, while carbon and nitrogen are depleted. Despite these changes in surface stoichiometry, we observe no effect on the work function. The absorbance and X-ray diffraction spectra show no changes other than the peaks diminishing with etch time. These findings have important implications for organic photovoltaic devices which seek nanopillar thin films of metal phthalocyanine materials as an optimal structure.
\end{abstract}

Keywords: phthalocyanine dyes; vapor phase processes; dry etching; nanopillar formation

\section{Introduction}

Ion sputtering is often employed by surface analysis techniques, such as auger electron spectroscopy (AES), X-ray photoelectron spectroscopy (XPS), and sary ion mass spectrometry (SIMS), to generate depth profiles of multilayer films. The limits imposed on depth profiling by the effects of ion sputtering on surface topography have been studied thoroughly for many metal and 
semiconductor thin films [1-11]. Ripples and cones are among the most common surface features produced by ion bombardment. The severity of surface topography changes during ion sputtering depends on the characteristics of the sample and the ion beam, and can often be reduced by means of sample rotation $[5,12,13]$. Accurate depth profiling of polymer and organic layers is considerably more challenging than inorganic materials, but has been improved as of late [14-20]. Few studies have been done on plasma etched metal phthalocyanine (MPc) films, and the effects on morphology are not well known.

This paper investigates the evolution of copper phthalocyanine $(\mathrm{CuPc})$ and zinc phthalocyanine $(\mathrm{ZnPc})$ thin films as they are etched with argon and oxygen plasmas. Significant morphological changes occur as a result of the ion bombardment: A planar surface becomes an array of nanopillars with sub-20 nm diameters. This result is intriguing from an organic photovoltaic perspective, where nanopillar film morphologies are desired whose pillar diameters closely match the short exciton diffusion lengths of around $15 \mathrm{~nm}$ seen in organic materials [21]. Many methods have been used to attempt this nanopillar morphology, such as solvent annealing [22], solvent recrystallization [23], organic vapor phase deposition [24], glancing angle deposition [25-29], substrate seeding [30,31], and heat treatments [32,33]. However, nanopillar films remain much less than $100 \mathrm{~nm}$ in thickness in most cases, which leaves absorption insufficient for achieving optimal device efficiencies. Therefore, alternative methods are desired for fabricating nanopillar organic films. Plasma etching presents an entirely new approach to structuring organic thin films at the nanoscale. In previous studies, ion bombardment has been found to induce surface texturing on various inorganic materials, which is often explained by the preferential erosion of grain boundaries $[2,34,35]$. The results presented in this paper exhibit similar behavior, enabling a new approach to nanostructuring MPc thin films.

\section{Results and Discussion}

\subsection{Columnar MPc Film Morphologies via Plasma Etching}

The first nanopillar films were fabricated by etching a set of $180 \mathrm{~nm}$ thick planar CuPc films with argon plasma. Films were etched with an RF power of $220 \mathrm{~W}$ for 20 and 40 ss, resulting in the columnar morphologies seen in Figure 1. With column diameters of around $20 \mathrm{~nm}$ or less, these morphologies are smaller than the columns found in the best small molecule films produced to date [33], and are extremely well suited to the exciton diffusion lengths of MPc materials. In addition, the etched columns in Figure 1c are wide at the base and taper off at the top, which may improve their survivability during the solution-based filling processes commonly used in OPV device fabrication.

Etching with oxygen gas instead of argon was also performed, with a chamber pressure of $150 \mathrm{mTorr}$, RF power of $220 \mathrm{~W}$, and gas flow rate of $80 \mathrm{sccm}$. The results are shown in Figure 2. Here, etching proceeded much faster due to the reactivity of ionized oxygen, which enhances removal of organic material in conjunction with physical sputtering. A somewhat similar final morphology can be achieved with oxygen plasma compared to argon plasma, albeit with a more disordered and fragile network of remaining features. The likelihood of chemical changes to the film is higher with oxygen, making oxygen plasma etched films less interesting than argon plasma etched films. As such, argon was determined to be the etching gas of choice, and no additional oxygen-etched films were investigated. 
Figure 1. Effects of argon plasma etching on a planar $\mathrm{CuPc}$ thin film.

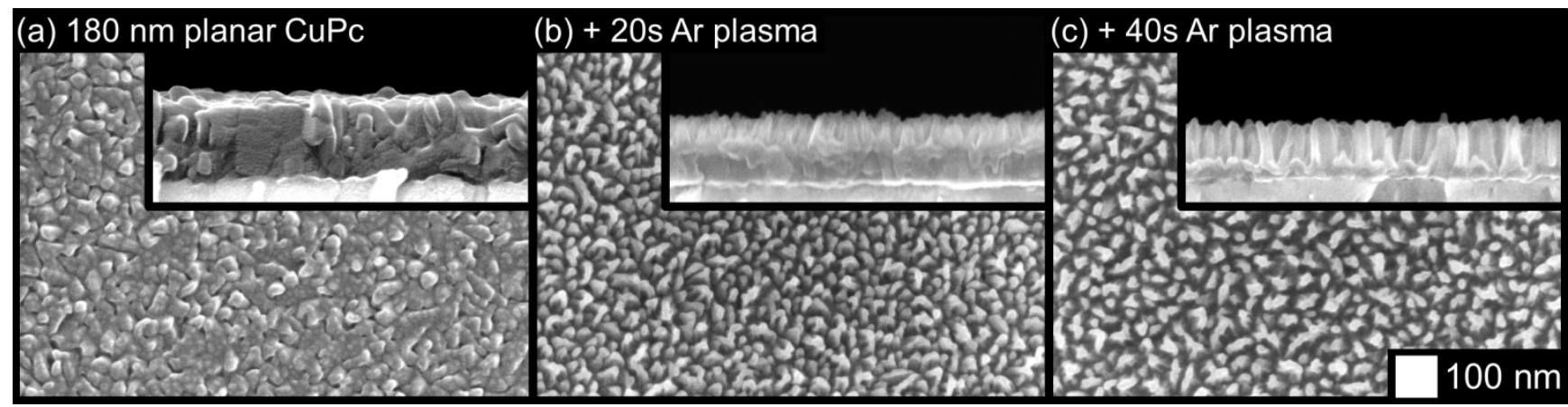

Figure 2. Effects of oxygen plasma etching on a planar $\mathrm{CuPc}$ thin film.

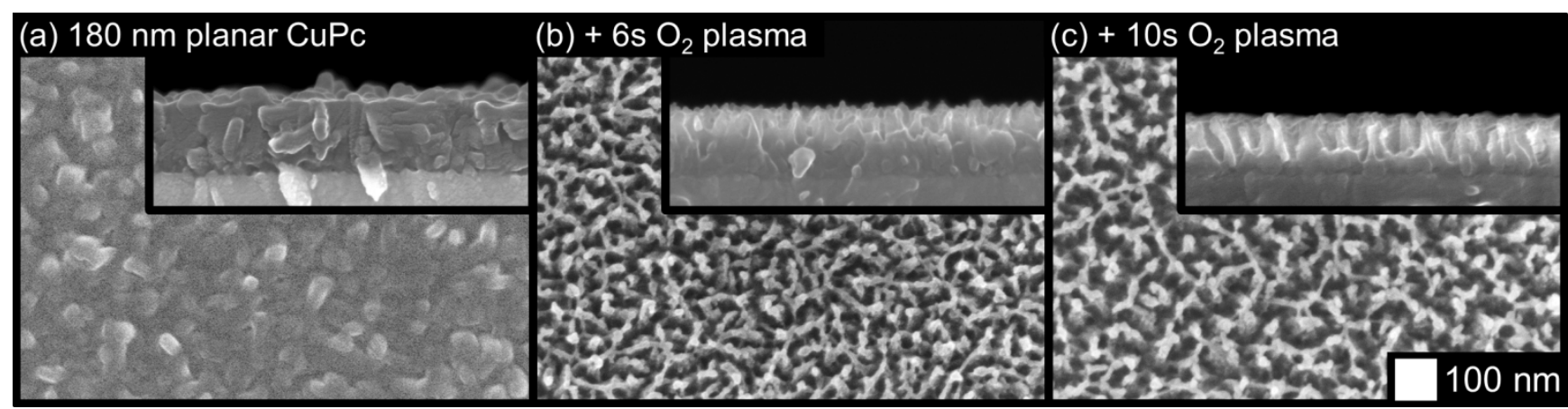

The RF power was varied to investigate the sensitivity of morphology to the etch conditions. A $300 \mathrm{~nm}$ planar film was exposed to argon plasmas for various periods of time with three levels of RF power: $73 \mathrm{~W}, 147 \mathrm{~W}$, and $220 \mathrm{~W}$. The images shown in Figure 3 reveal similar etching behavior in all cases, only at different rates. Etched films resembled others that were etched to similar depths under different conditions. Thus, the etching mechanism remains the same, and changes in RF power affect the etch rate only.

Figure 3. Effects of different etch conditions and etch times on the morphology of CuPc thin films etched with argon plasma.

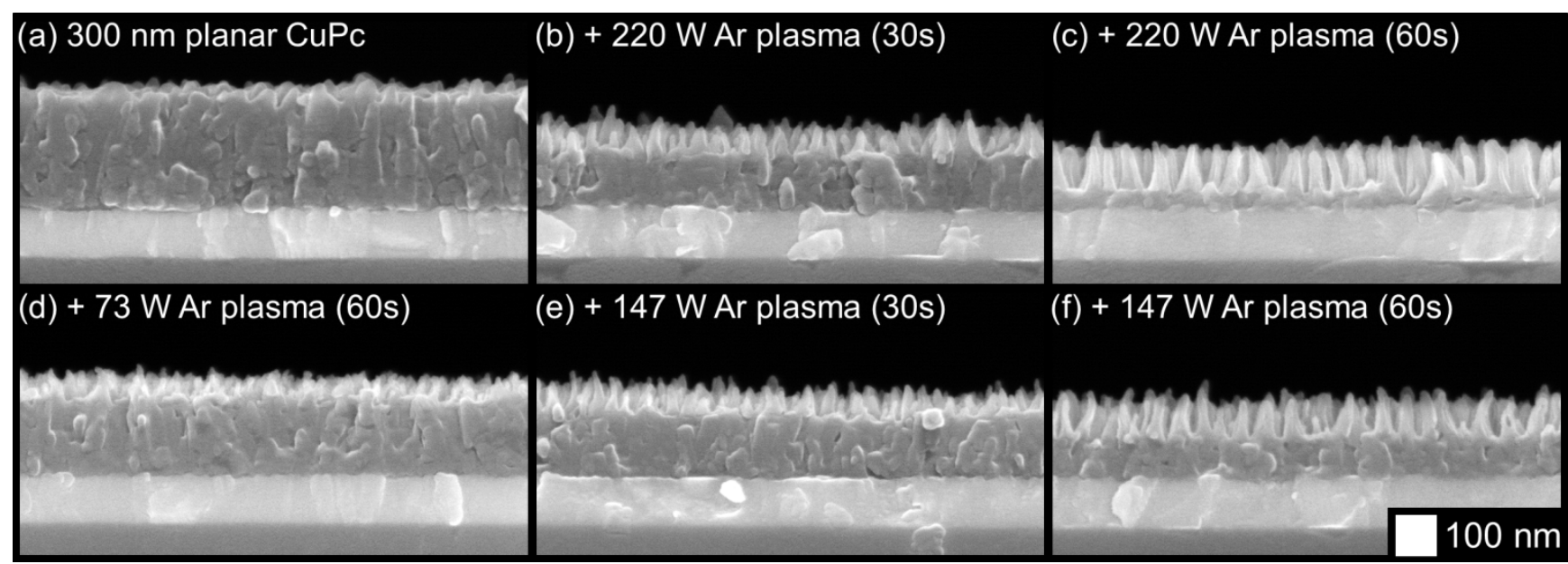

It may be possible to further improve these etched film morphologies by starting with an already textured MPc film. For example, glancing angle deposition (GLAD) has been used previously to grow 
nanopillar MPc films suitable for OPV devices [25-29]. GLAD is a physical vapor deposition technique that produces nanopillar film morphologies by placing the substrate at an oblique angle relative to incoming vapor flux [36]. Combining GLAD with plasma etching could introduce additional control over columnar dimensions and spacing, while requiring less etching and disturbance of the original film. Alternatively, this approach can be thought of as a way to refine the structure of a GLAD film via ion bombardment, which is not an entirely new concept. In fact, ion milling and reactive ion etching have been shown previously to enhance the morphology and properties of GLAD films for various inorganic materials in other applications [37-41]. Figure 4 shows the effects of etching a $120 \mathrm{~nm}$ GLAD ZnPc film. The original film has a slanted post morphology (pointing into the page), which appears largely untouched by a low power etch but deteriorates significantly under a more aggressive etch (Figure $4 \mathrm{~b} v s .4 \mathrm{c}$ ), with an overall thinning of the areal density of posts observed. In these cases, any structural enhancements due to etching are not obvious. It is possible that a vertical post morphology may be more receptive to plasma etch refinements, and that thicker films with broader columns would benefit more, but this will require further study.

Figure 4. Effects of different argon plasma etching conditions on a thin GLAD ZnPc film.

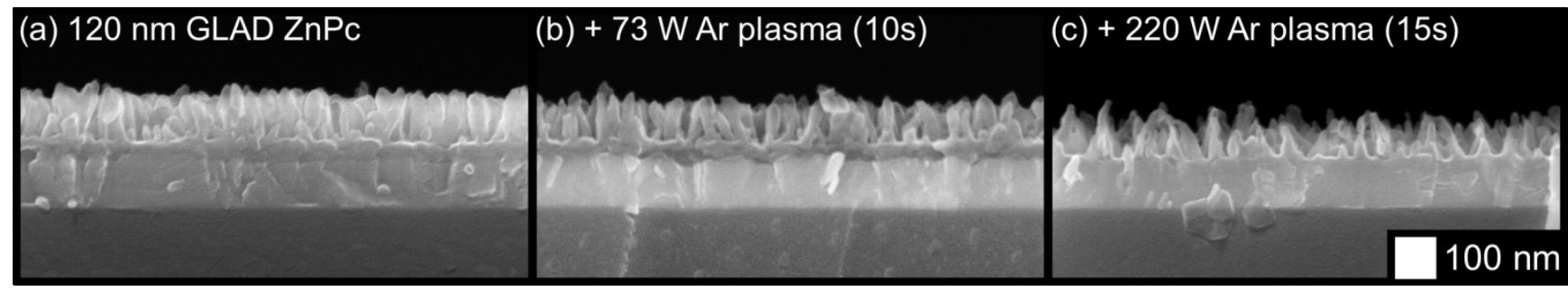

\subsection{Surface Analysis and Electronic Properties}

The creation of columnar film morphologies out of planar ones with ion sputtering potentially affects the surface composition. The harmful effects of UV radiation from the plasma alone may impact the survivability of the sample $[42,43]$. In addition, when considering that the ion energies from the plasma are at least comparable to or greater than the intramolecular bond energies in metal phthalocyanines, changes in surface composition may be expected $[44,45]$. Unsurprisingly, ion beams with $\mathrm{MeV}$ ion energies have been shown to be very destructive to MPc molecules [46]. However, the strong $\pi$ network of MPc molecules may help them avoid fragmentation from impacts of only tens of $\mathrm{eV}$, due to protection by delocalized electrons [47].

The surfaces of the etched CuPc films in this investigation were analyzed with ultraviolet photoelectron spectroscopy (UPS) and X-ray photoelectron spectroscopy (XPS). The UPS curves, shown in Figure 5, show virtually no change in the onset energy for electron ejection, at around $16.5 \mathrm{eV}$. Consequently, the work function is consistent across all samples, at $4.7 \pm 0.1 \mathrm{eV}$, which is slightly higher than other published values [48,49], but may be simply due to more air exposure [50]. These results provide little insight into the effects of etching, and direct contact resistance measurements could not be performed due to the mechanical sensitivity of the nanopillar films. However, analysis by XPS reveals more significant information. 
Figure 5. Changes to the UPS spectra of a planar CuPc film due to argon plasma etching.

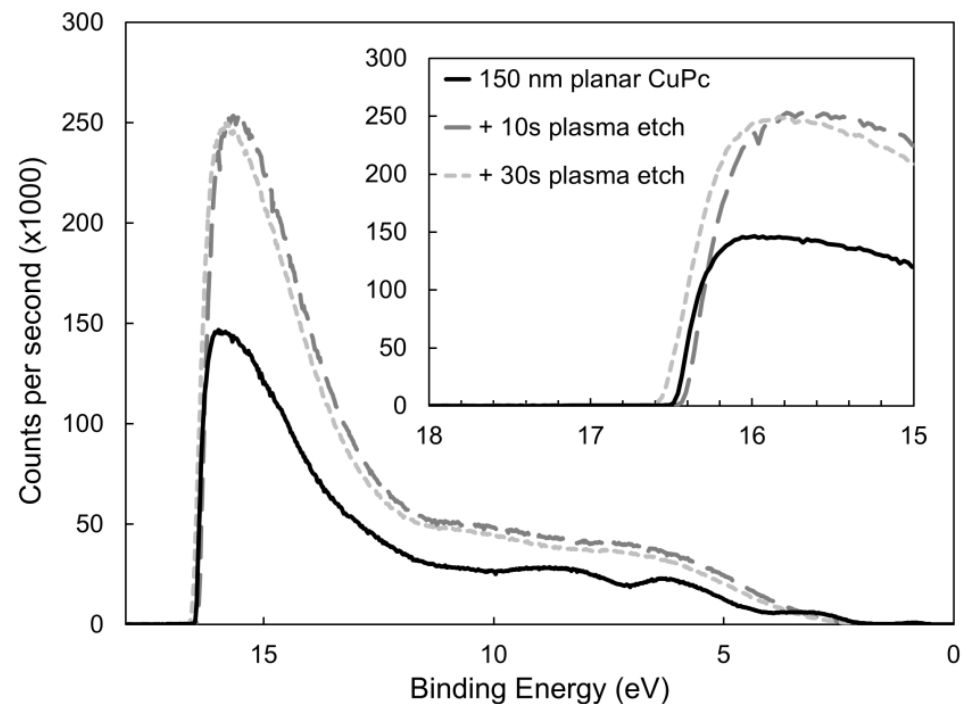

The atomic concentrations of various elements were calculated from the relative XPS peak heights, and are presented in Figure 6. Significant and immediate removal of $\mathrm{C}$ and $\mathrm{N}$ is evident in the sample etched for $10 \mathrm{~s}$, which does not change much further in the $30 \mathrm{~s}$ etch. Meanwhile, higher concentrations of $\mathrm{Cu}$ are revealed by the etching, which is consistent with results from other etch chemistries [45]. Evidently, the CuPc molecules are not surviving the impacts of the Ar ions, and lighter elements are being preferentially removed over heavier ones. Interestingly, a significant amount of $\mathrm{O}$ and $\mathrm{F}$ are introduced to the surface, which are likely the result of residual gases in the etch chamber binding to the fragmented molecules as a means of stabilization. For device quality $\mathrm{CuPc}$ it may be necessary to perform the etching in a UHV environment. The composition of the original planar $\mathrm{CuPc}$ film is independent of the incident beam angle, which suggests that the surface and subsurface are very similar. For the etched films, however, the surface is slightly richer in $\mathrm{Cu}$ while being depleted of $\mathrm{C}$ and $\mathrm{N}$, which confirms the preferential removal of $\mathrm{C}$ and $\mathrm{N}$ over $\mathrm{Cu}$ mentioned previously. These changes to surface composition may impact potential functionality of the $\mathrm{CuPc}$ nanopillars at the active layer interface of an OPV device.

Figure 6. Changes to the surface composition of a planar $\mathrm{CuPc}$ film due to argon plasma etching.

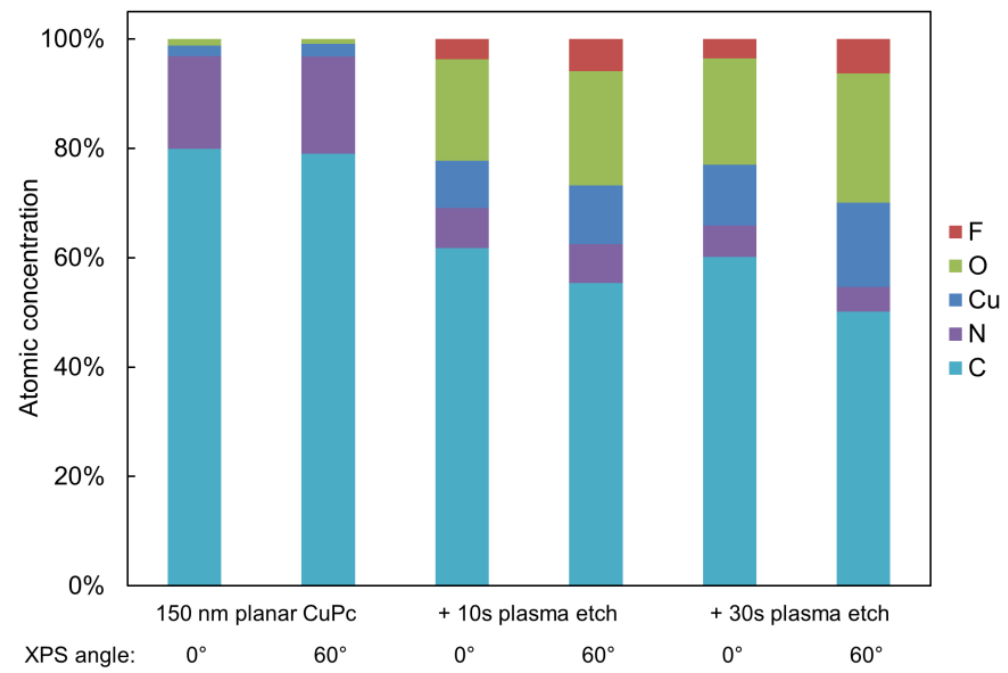




\subsection{Bulk Film Analysis}

The surface composition modifications shown in the previous section warrant a study of the bulk properties of the remaining film. Absorbance profiles were gathered in both the visible and infrared spectral regions, which are shown in Figures 7 and 8, respectively. In both cases, no changes to the shape of the absorbance spectra are seen as a result of the etching, but only diminished peak heights. This is consistent with the removal of material seen by SEM, and confirms that much of the remaining film avoids being damaged. Likewise, the X-ray diffraction (XRD) profiles shown in Figure 9 show no changes other than peaks diminishing with etch time. Thus, the material that does remain in the film appears to maintain both its molecular and crystalline structure. It is significant to note that the most etched CuPc film in Figure 7 maintains comparable absorbance to a $120 \mathrm{~nm}$ planar un-etched film. Therefore, these films possess nearly the same amount of $\mathrm{CuPc}$ material, equivalent to six times the amount used in a typical bilayer OPV device [21]. This confirms that the film morphology seen in Figure $3 \mathrm{c}$ is suitable as an ideal OPV active layer architecture. Every point of light absorption in this nanopillar film would be within a single exciton diffusion length of the donor/acceptor interface, and the film would capture significantly more incident light than a commonly used $20 \mathrm{~nm}$ planar layer. If the interface were functional, the architecture fabricated by plasma etching would be very useful.

Figure 7. Changes to thin film absorbance as a result of argon plasma etching.

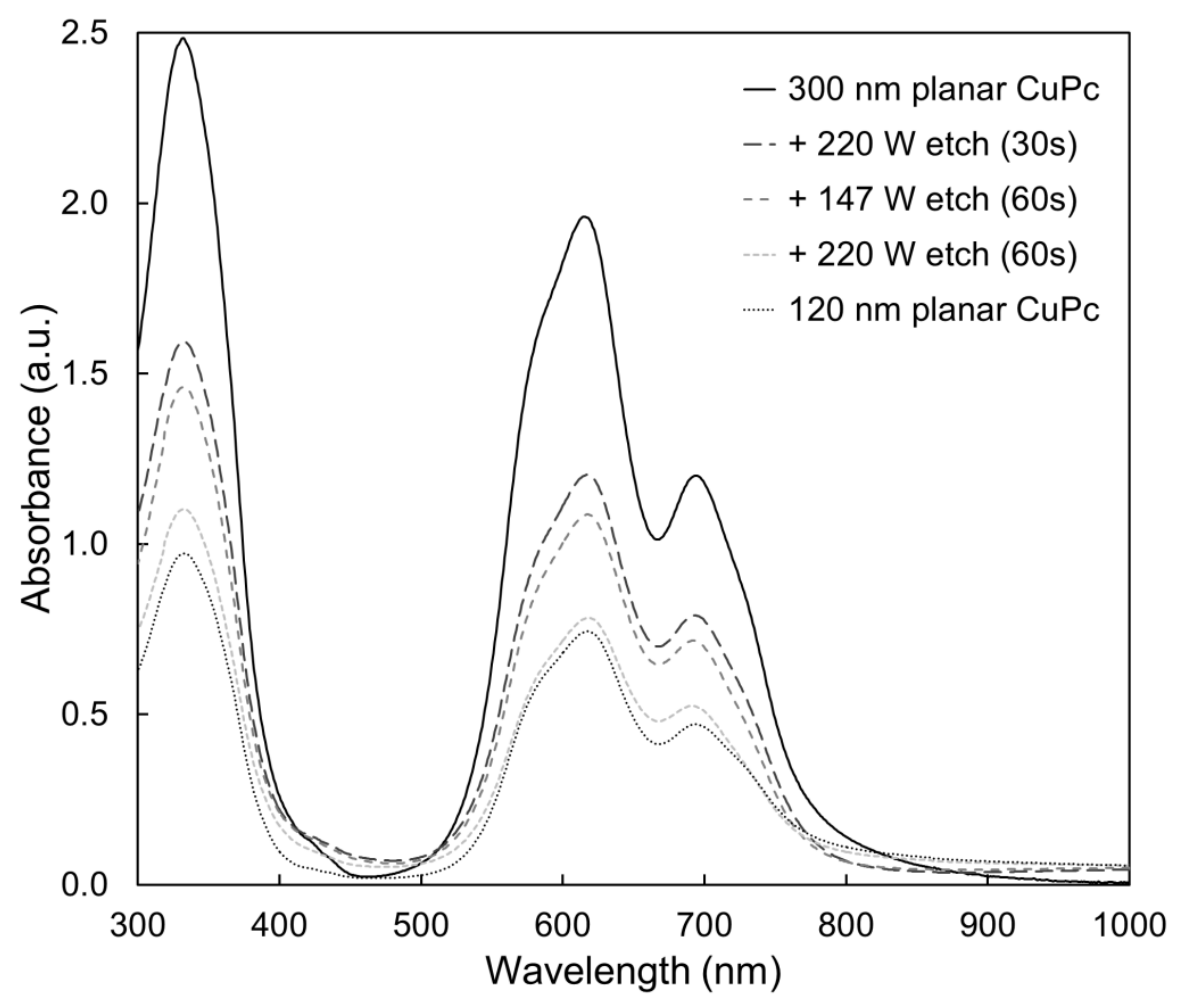

Alternative sputtering techniques may enable structuring of MPc films while minimizing surface damage. Recently, $\mathrm{C}_{60}$ ion beams have been used to minimize sputtering damage to organic films during analysis [16-20]. Increasing the incident angle of the ion beam has been found to further minimize sputtering damage [20]. 
Figure 8. Changes to FTIR absorbance spectra of a CuPc thin film due to $220 \mathrm{~W}$ argon plasma etching.

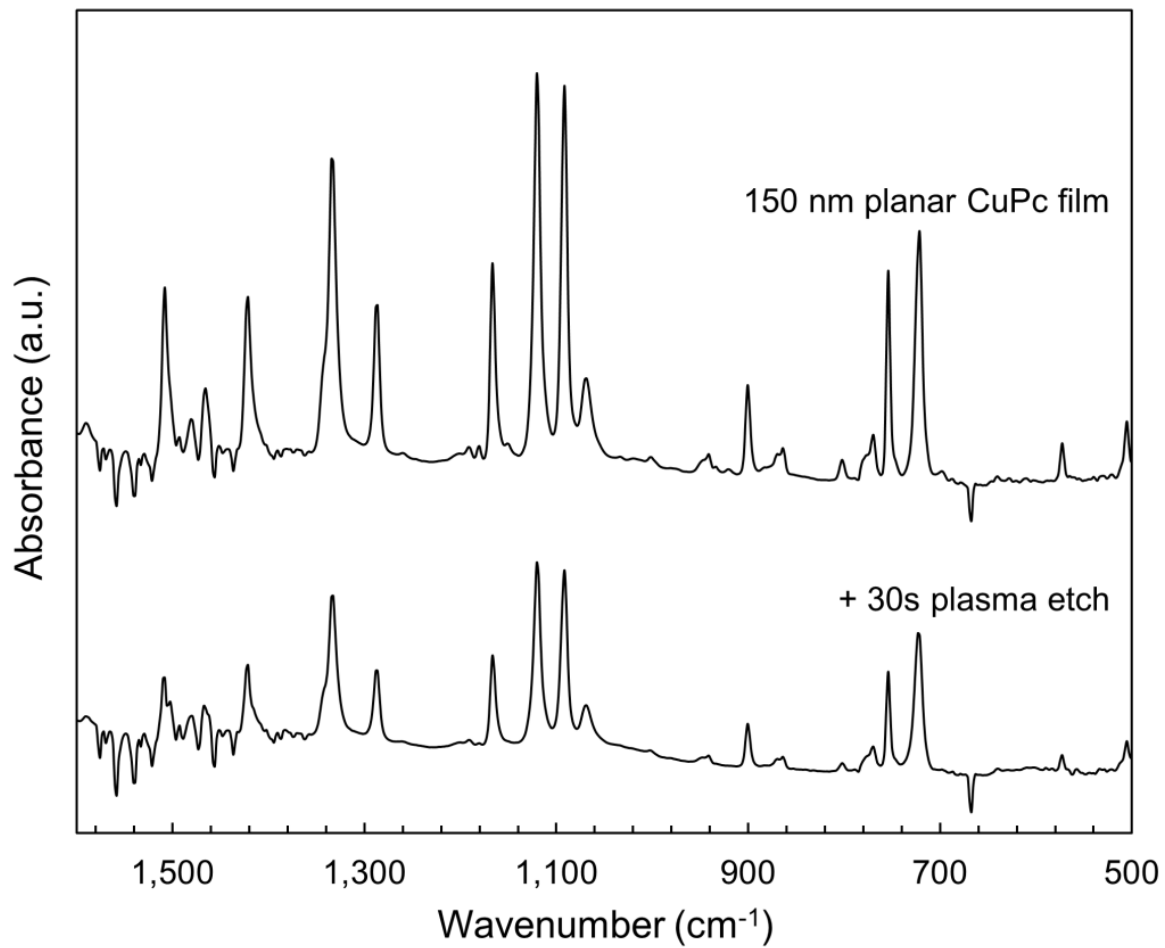

Figure 9. Changes to the XRD spectrum of a planar CuPc thin film as a result of $220 \mathrm{~W}$ argon plasma etching.

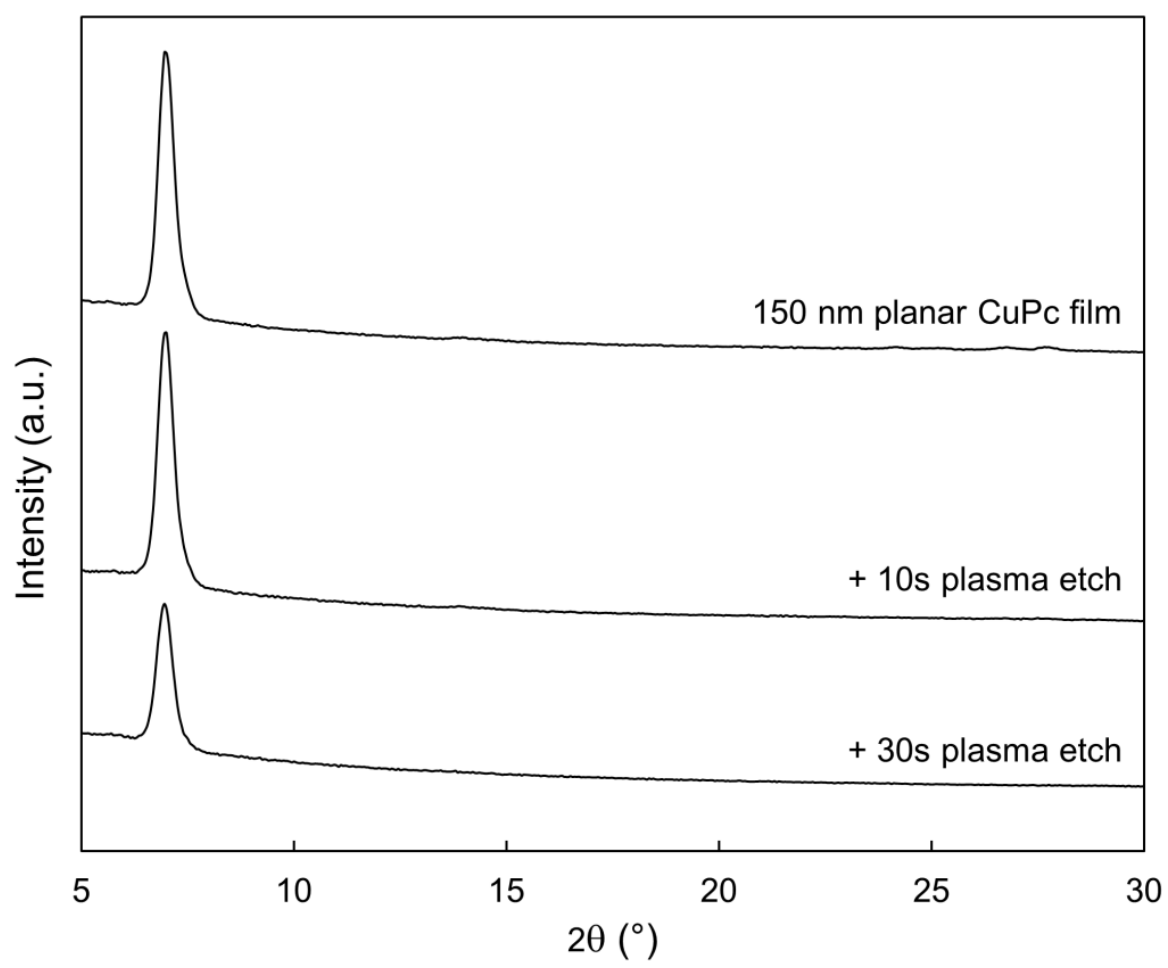

Coincidentally, $\mathrm{C}_{60}$ is the acceptor molecule commonly used with MPc materials in the active layer of small molecule OPV devices. This may be very suitable if ion energies are used that are conducive 
to maintaining molecular structure, particularly since any residue in the film from the ion beam may be functional in the active layer. Therefore, attempting damage-free, ion-induced structuring of MPc films with $\mathrm{C}_{60}$ is worthy of further investigation.

\section{Experimental}

$\mathrm{CuPc}$ and $\mathrm{ZnPc}$ were purchased from Sigma-Aldrich (Oakville, ON, Canada) and purified via thermal gradient sublimation prior to deposition. Both planar and GLAD thin films were deposited in a standard GLAD apparatus [36] via thermal evaporation, with a throw distance of $34 \mathrm{~cm}$, a source temperature of about $400{ }^{\circ} \mathrm{C}$, a base pressure of $2 \times 10^{-7}$ Torr, and a deposition rate of $0.7 \AA / \mathrm{s}$ normal to the surface. A variety of substrates were used, to enable various characterization techniques. ITO-coated glass (Delta Technologies, 8-12 $\Omega / \Upsilon$ ) was used for imaging via SEM; Si wafers (Evergreen Semiconductor Materials) were used for analysis by XRD, XPS, and UPS; KBr discs (Fisher Scientific) were used to gather FTIR profiles; and glass microscope slides (Fisher Scientific) were used for UV/Vis absorbance profiles. Argon plasma etching was performed in an Oxford Plasmalab $\mu$ Etch RIE chamber, with $110 \mathrm{sccm}$ Ar gas flow and a chamber pressure of $190 \mathrm{mTorr}$. The standard RF power used was $220 \mathrm{~W}$, but was changed on occasion, as explained in the text.

Electron microscope images were acquired using a Hitachi field emission S-4800 SEM. XPS was performed at high vacuum $\left(<5 \times 10^{-10}\right.$ Torr $)$ with a Kratos Ultra spectrometer, using a $\mathrm{Al} \mathrm{K} \alpha$ radiation source $(\mathrm{h} v=1,486.71 \mathrm{eV})$. Measurements were done using incident beam angles of $0^{\circ}$ and $60^{\circ}$ to probe different surface depths. Atomic concentrations were calculated using the relative peak intensities while accounting for the atomic sensitivity factors. UPS was performed in the same environment as XPS, using a He I $(\mathrm{h} v=21.21 \mathrm{eV})$ radiation source. Absorbance over visible regions was acquired as the negative logarithm of transmittance, using a Perkin Elmer Lambda 900 UV/VIS/NIR spectrophotometer. Infrared absorbance was captured with a Nicolet Nexus 760 FTIR spectrometer with a DTGS detector and a sample chamber purged with $\mathrm{N}_{2}$. XRD data was collected with a Bruker D8 diffractometer, equipped with a $\mathrm{Cu}$ source and area detector, and calibrated against a silver behenate reference standard.

\section{Conclusions}

This paper investigated the effects of argon plasma etching on metal phthalocyanine thin films. Planar films of these materials are readily transformed into nanopillar films with dimensions extremely well suited to OPV devices. The films maintain much of their original molecular characteristics, such as absorbance profiles and crystalline order. However, changes to the surface composition suggest that the ion bombardment causes fragmentation of the molecules at the film surface. Avoiding or repairing this surface damage is necessary to enable functionality in OPV devices, which could provide a new approach to building idealized organic photovoltaic architectures.

\section{Acknowledgments}

The authors acknowledge the gracious financial support of the Natural Sciences and Engineering Research Council of Canada (NSERC), Alberta Innovates Technology Futures (AITF), Micralyne Inc., 
the University of Alberta, and the National Research Council-National Institute for Nanotechnology (NRC-NINT). JV acknowledges NSERC, AITF, SPIE, and the Golden Key International Honour Society for scholarship support. The authors also thank Michael Fleischauer for XRD analysis, the NINT microscopy group, the University of Alberta Nanofab, and the Alberta Centre for Surface Engineering and Science (ACSES) for XPS and UPS analysis.

\section{References}

1. Nobes, M.J.; Colligon, J.S.; Carter, G. The equilibrium topography of sputtered amorphous solids. J. Mater. Sci. 1969, 4, 730-733.

2. Auciello, O.; Kelly, R. Ion Bombardment Modification of Surfaces; Elsevier Publishing Co.: Amsterdam, The Netherlands, 1984.

3. King, B.V.; Tsong, I.S.T. The depth resolution of sputter profiling. Ultramicroscopy 1984, 14, $75-78$.

4. Tanemura, M.; Okuyama, F. Topographical features of $\mathrm{N}_{2}{ }^{+}$-Sputtered Metal Sandwiches: Their Correlation with Auger Depth Resolution. Thin Solid Films 1988, 165, 193-209.

5. Cirlin, E.-H.; Vajo, J.J.; Doty, R.E.; Hasenberg, T.C. Ion-induced topography, depth resolution, and ion yield during sary ion mass spectrometry depth profiling of a GaAs/AlGaAs superlattice: Effects of sample rotation. J. Vac. Sci. Technol. A 1991, 9, 1395-1401.

6. Hofmann, S. Approaching the limits of high resolution depth profiling. Appl. Surf. Sci. 1993, 70-71, 9-19.

7. Carter, G. The effects of ion bombardment sputtering and atomic transport related roughening and smoothing on depth profiling resolution. Vacuum 1996, 47, 409-420.

8. Carter, G. The physics and applications of ion beam erosion. J. Phys. D Appl. Phys. 2001, 34, R1-R22.

9. Karmakar, P.; Mollick, S.A.; Ghose, D.; Chakrabarti, A. Role of initial surface roughness on ion induced surface morphology. Appl. Phys. Lett. 2008, 93, 103102.

10. Sulania, I.; Tripathi, A.; Kabiraj, D.; Lequeux, M.; Avasthi, D. Surface patterning on indium phosphide with low energy Ar atoms bombardment: an evolution from nanodots to nanoripples. Adv. Mat. Lett. 2010, 1, 118-122.

11. Zhang, K.; Brötzmann, M.; Hofsäss, H. Surfactant-driven self-organized surface patterns by ion beam erosion. New J. Phys. 2011, 13, 013033.

12. Pamler, W.; Wangemann, K.; Kampermann, S.; Hosler, W. Depth Resolution in Auger Depth Profile Analysis of Aluminum Metallization in Microelectronics: The Effect of Crystalline Texture. Nucl. Instrum. Methods 1990, 51, 34-40.

13. Tanemura, M.; Fujimoto, S.; Okuyama, F. Dependence of Auger Depth Resolution and Surface Texturing on Primary Ion Species. Surf. Sci. 1990, 230, 283-289.

14. Cramer, H.-G.; Grehl, T.; Kollmer, F.; Moellers, R.; Niehuis, E.; Rading, D. Depth profiling of organic materials using improved ion beam conditions. Appl. Surf. Sci. 2008, 255, 966-969. 
15. Ninomiya, S.; Ichiki, K.; Yamada, H.; Nakata, Y.; Seki, T.; Aoki, T.; Matsuo, J. Molecular depth profiling of multilayer structures of organic semiconductor materials by sary ion mass spectrometry with large argon cluster ion beams. Rapid Commun. Mass Spectrom. 2009, 23, 3264-3268.

16. Weibel, D.E.; Lockyer, N.; Vickerman, J.C. $\mathrm{C}_{60}$ cluster ion bombardment of organic surfaces. Appl. Surf. Sci. 2004, 231-232, 153-158.

17. Jones, E.A.; Fletcher, J.S.; Thompson, C.E.; Jackson, D.A.; Lockyer, N.P.; Vickerman, J.C. ToF-SIMS analysis of bio-systems: Are polyatomic primary ions the solution? Appl. Surf. Sci. 2006, 252, 6844-6854.

18. Winograd, N.; Postawa, Z.; Cheng, J.; Szakal, C.; Kozole, J.; Garrison, B.J. Improvements in SIMS continue-Is the end in sight? Appl. Surf. Sci. 2006, 252, 6836-6843.

19. Shon, H.K.; Lee, T.G.; Kim, D.H.; Kang, H.J.; Lee, B.H.; Sung, M.M.; Moon, D.W. The effect of $\mathrm{C}_{60}$ cluster ion beam bombardment in sputter depth profiling of organic-inorganic hybrid multiple thin films. Appl. Surf. Sci. 2008, 255, 1055-1057.

20. Miyayama, T.; Sanada, N.; Iida, S.-I.; Hammond, J.S.; Suzuki, M. The effect of angle of incidence to low damage sputtering of organic polymers using a $\mathrm{C}_{60}$ ion beam. Appl. Surf. Sci. 2008, 255, 951-953.

21. Yang, F.; Forrest, S.R. Photocurrent generation in nanostructured organic solar cells. ACS Nano 2008, 2, 1022-1032.

22. Placencia, D.; Wang, W.; Shallcross, R.C.; Nebesny, K.W.; Brumbach, M.; Armstrong, N.R. Organic Photovoltaic Cells Based On Solvent-Annealed, Textured Titanyl Phthalocyanine/ $\mathrm{C}_{60}$ Heterojunctions. Adv. Funct. Mater. 2009, 19, 1913-1921.

23. Karak, S.; Ray, S.K.; Dhar, A. Improvement of efficiency in solar cells based on vertically grown copper phthalocyanine nanorods. J. Phys. D Appl. Phys. 2010, 43, 245101.

24. Yang, F.; Shtein, M.; Forrest, S.R. Controlled growth of a molecular bulk heterojunction photovoltaic cell. Nat. Mater. 2005, 4, 37-41.

25. Van Dijken, J.G.; Fleischauer, M.D.; Brett, M.J. Morphology control of CuPc thin films using Glancing Angle Deposition. In Proceedings of 33rd IEEE Photovoltaic Specialists Conference, San Diego, CA, USA, 11-16 May 2008; pp. 1222-1225.

26. Zheng, Y.; Bekele, R.; Ouyang, J.; Xue, J. Organic photovoltaic cells with vertically aligned crystalline molecular nanorods. Org. Electron. 2009, 10, 1621-1625.

27. Li, N.; Forrest, S.R. Tilted bulk heterojunction organic photovoltaic cells grown by oblique angle deposition. Appl. Phys. Lett. 2009, 95, 123309.

28. Van Dijken, J.G.; Fleischauer, M.D.; Brett, M.J. Controlled nanostructuring of CuPc thin films via glancing angle deposition for idealized organic photovoltaic architectures. J. Mater. Chem. 2011, 21, 1013-1019.

29. Van Dijken, J.G.; Fleischauer, M.D.; Brett, M.J. Solvent effects on ZnPc thin films and their role in fabrication of nanostructured organic solar cells. Org. Electron. 2011, 12, 2111-2119.

30. Hirade, M.; Nakanotani, H.; Yahiro, M.; Adachi, C. Formation of organic crystalline nanopillar arrays and their application to organic photovoltaic cells. ACS Appl. Mater. Interfaces 2011, 3, $80-83$. 
31. Van Dijken, J.G.; Wu, N.L.-Y.; Fleischauer, M.D.; Buriak, J.M.; Brett, M.J. Morphology control and nanoscale patterning of small molecule organic thin films. SPIE 2012, 8435, 8435R.

32. Pfuetzner, S.; Mickel, C.; Jankowski, J.; Hein, M.; Meiss, J.; Schuenemann, C.; Elschner, C.; Levin, A.A.; Rellinghaus, B.; Leo, K.; et al. The influence of substrate heating on morphology and layer growth in $\mathrm{C}_{60}: \mathrm{ZnPc}$ bulk heterojunction solar cells. Org. Electron. 2011, 12, 435-441.

33. Matsuo, Y.; Sato, Y.; Niinomi, T.; Soga, I.; Tanaka, H.; Nakamura, E. Columnar structure in bulk heterojunction in solution-processable three-layered $\mathrm{p}-\mathrm{i}-\mathrm{n}$ organic photovoltaic devices using tetrabenzoporphyrin precursor and silylmethyl[60]fullerene. J. Am. Chem. Soc. 2009, 131, $16048-16050$.

34. Auciello, O. Ion interaction with solids: Surface texturing, some bulk effects, and their possible applications. J. Vac. Sci. Technol. 1981, 19, 841-867.

35. Cuomo, J.J.; Rossnagel, S.M.; Kaufman, H.R. Handbook of Ion Beam Processing Technology-Principles, Deposition, Film Modification and Synthesis; Noyes Publications: Park Ridge, NJ, USA, 1989.

36. Hawkeye, M.M.; Brett, M.J. Glancing angle deposition: Fabrication, properties, and applications of micro- and nanostructured thin films. J. Vac. Sci. Technol. A 2007, 25, 1317-1335.

37. Sorge, J.B.; Brett, M.J. Film morphology modification in ion-assisted glancing angle deposition. Thin Solid Films 2010, 519, 1356-1360.

38. Taschuk, M.T.; Sorge, J.B.; Steele, J.J.; Brett, M.J. Ion-Beam Assisted Glancing Angle Deposition for Relative Humidity Sensors. IEEE Sens. J. 2008, 8, 1521-1522.

39. Kupsta, M.R.; Taschuk, M.T.; Brett, M.J.; Sit, J.C. Reactive Ion Etching of Columnar Nanostructured $\mathrm{TiO}_{2}$ Thin Films for Modified Relative Humidity Sensor Response Time. IEEE Sens. J. 2009, 9, 1979-1986.

40. Kwan, J.K.; Sit, J.C. The use of ion-milling to control clustering of nanostructured, columnar thin films. Nanotechnology 2010, 21, 295301.

41. Jim, S.R.; Oko, A.J.; Taschuk, M.T.; Brett, M.J. Morphological modification of nanostructured ultrathin-layer chromatography stationary phases. J. Chromatogr. A 2011, 1218, 7203-7210.

42. Peters, C.H.; Sachs-Quintana, I.T.; Kastrop, J.P.; Beaupré, S.; Leclerc, M.; McGehee, M.D. High Efficiency Polymer Solar Cells with Long Operating Lifetimes. Adv. Energy Mater. 2011, 1, 491-494.

43. Jørgensen, M.; Norrman, K.; Krebs, F.C. Stability/degradation of polymer solar cells. Sol. Energy Mater. Sol. Cells 2008, 92, 686-714.

44. Naddaf, M.; Chakane, S.; Jain, S.; Bhoraskar, S.V.; Mandale, A.B. Modification of sensing properties of metallophthalocyanine by an ECR plasma. Nucl. Instrum. Meth. B 2002, 194, 54-60.

45. Pakhomov, G.L.; Drozdov, M.N.; Vostokov, N.V. Plasma irradiation effects in phthalocyanine films. Appl. Surf. Sci. 2004, 230, 241-248.

46. Kaplan, M.L.; Forrest, S.R.; Schmidt, P.H.; Venkatesan, T. Optical and electrical properties of ion-beam-irradiated films of organic molecular solids and polymers. J. Appl. Phys. 1984, 55, 732.

47. Nath, A.; Prushan, M.J.; Gilbert, J.G. Can super-excited molecules survive fragmentation? J. Radioanal. Nucl. Chem. 2001, 247, 589-591. 
48. Wei, H.X.; Li, J.; Xu, Z.Q.; Cai, Y.; Tang, J.X.; Li, Y.Q. Thermal annealing-induced vertical phase separation of copper phthalocyanine: Fullerene bulk heterojunction in organic photovoltaic cells. Appl. Phys. Lett. 2010, 97, 083302.

49. Wei, H.X.; Li, J.; Cai, Y.; Xu, Z.Q.; Lee, S.T.; Li, Y.Q.; Tang, J.X. Electronic structures of planar and mixed $\mathrm{C}_{70} / \mathrm{CuPc}$ heterojunctions in organic photovoltaic devices. Org. Electron. 2011, 12, $1422-1428$.

50. Grządziel, L.; Krzywiecki, M.; Peisert, H.; Chassé, T.; Szuber, J. Influence of ambient air exposure on surface chemistry and electronic properties of thin copper phthalocyanine sensing layers. Thin Solid Films 2011, 519, 2187-2192.

Sample Availability: Samples of the films are not available from the authors.

(C) 2012 by the authors; licensee MDPI, Basel, Switzerland. This article is an open access article distributed under the terms and conditions of the Creative Commons Attribution license (http://creativecommons.org/licenses/by/3.0/). 